\title{
Acute type A aortic dissection complicated with an aorto-right atrial fistula
}

\author{
Yuichiro Kitada, MD, Mamoru Arakawa, MD, PhD, Atsushi Miyagawa, MD, and \\ Homare Okamura, MD, PhD, Tokyo, Japan
}

From the Department of Cardiovascular Surgery, Nerima Hikarigaoka Hospital, Tokyo, Japan.

Disclosures: Authors have nothing to disclose with regard to commercial support.

Received for publication Oct 1, 2019; revisions received Oct 1, 2019; accepted for publication Jan 3, 2020; available ahead of print Feb 6, 2020

Address for reprints: Homare Okamura, MD, PhD, 2-11-1 Hikarigaoka, Nerima-Ku, Tokyo 179-0072, Japan (E-mail: homareo@jadecom.jp).

JTCVS Techniques 2020;1:1-3

2666-2507

Copyright (C) 2020 The Author(s). Published by Elsevier Inc. on behalf of The American Association for Thoracic Surgery. This is an open access article under the CC BY-NC-ND license (http://creativecommons.org/licenses/bync-nd/4.0/).

https://doi.org/10.1016/j.xjtc.2020.01.016

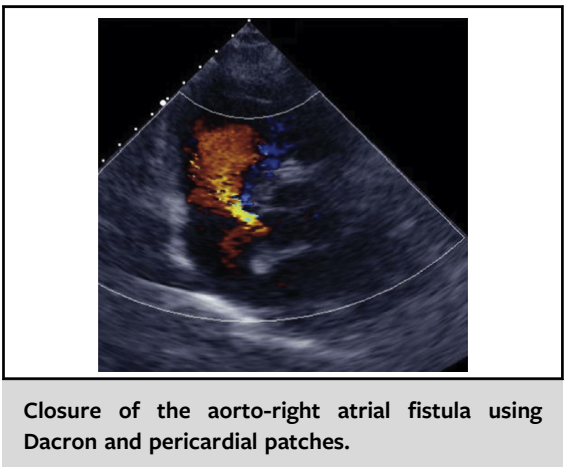

Video clip is available online.

\section{CENTRAL MESSAGE \\ Patch repair was successfully performed for the aorto-right atrial fistula associated with the acute type A aortic dissection.}

See Commentaries on pages 4 and 5 .
Acute type A aortic dissection frequently results in aortic rupture into the pericardial space. Herein, we describe a rare case of acute type $\mathrm{A}$ aortic dissection that ruptured into the right atrium resulting in the formation of an aorto-right atrial fistula.

\section{CLINICAL SUMMARY}

A 50-year-old man who presented with chest pain and dyspnea was transferred to our institution. On arrival, blood pressure was $120 / 50 \mathrm{~mm} \mathrm{Hg}$ and percutaneous oxygen saturation was $98 \%$ at $6 \mathrm{~L}$ of oxygen. A chest radiograph revealed moderate pulmonary congestion. Contrastenhanced computed tomography revealed a type A aortic dissection from the aortic root down to the right femoral artery and, notably, the communication between the false lumen of the aortic root and the right atrium (Figure 1, A). Transthoracic echocardiography (TTE) revealed preserved left ventricular function without pericardial effusion and a shunt flow from the aorta to the right atrium (Figure 1, B).

With the diagnosis of an acute type A aortic dissection complicated by an aorto-right atrial fistula (Figure 1,C), emergency surgery was performed. Intraoperative transesophageal echocardiography also confirmed the left-to-right shunt flow (Figure 1,D). Cardiopulmonary bypass (CPB) was initiated through cannulation of the ascending aorta, the superior and inferior vena cava, and a left ventricular vent. Hypothermic circulatory arrest was performed at a rectal temperature of $25^{\circ} \mathrm{C}$. Retrograde and antegrade cold blood cardioplegia were intermittently administered. Antegrade selective cerebral perfusion was initiated. The intimal tear near the innominate artery was excised. After transecting the aorta proximal to the left subclavian artery, a frozen elephant trunk (Frozenix J Graft; Japan Lifeline, Tokyo, Japan) was deployed with a fenestration created on the left subclavian artery side of the frozen elephant trunk and, subsequently, a 4-branched J-graft (Japan Lifeline) was anastomosed to the transected aorta with continuous 4-0 polypropylene sutures. ${ }^{1}$

From an interior view of the aorta, the sinus of Valsalva and aortic valve showed no issues. The adventitia of the aorta above the commissure, between the noncoronary cusp and the right coronary cusp, was torn and ruptured into the right atrium (Figure 2, $A$, and Video 1). The tear of the adventitia was located in the proximal blind end of the false lumen and direct closure of the ruptured adventitia was technically difficult. Therefore, we closed the fistula using 2 patches. Horizontal mattress sutures using 2-0 polyester sutures were passed through around the fistula from the right atrium to the inside of the aorta with reinforcement of a Dacron patch on the right atrium side and an autologous pericardium inside the aorta (Figure 2, $B$ and $C$, and Video 1). Subsequently, proximal anastomosis and reconstruction of 


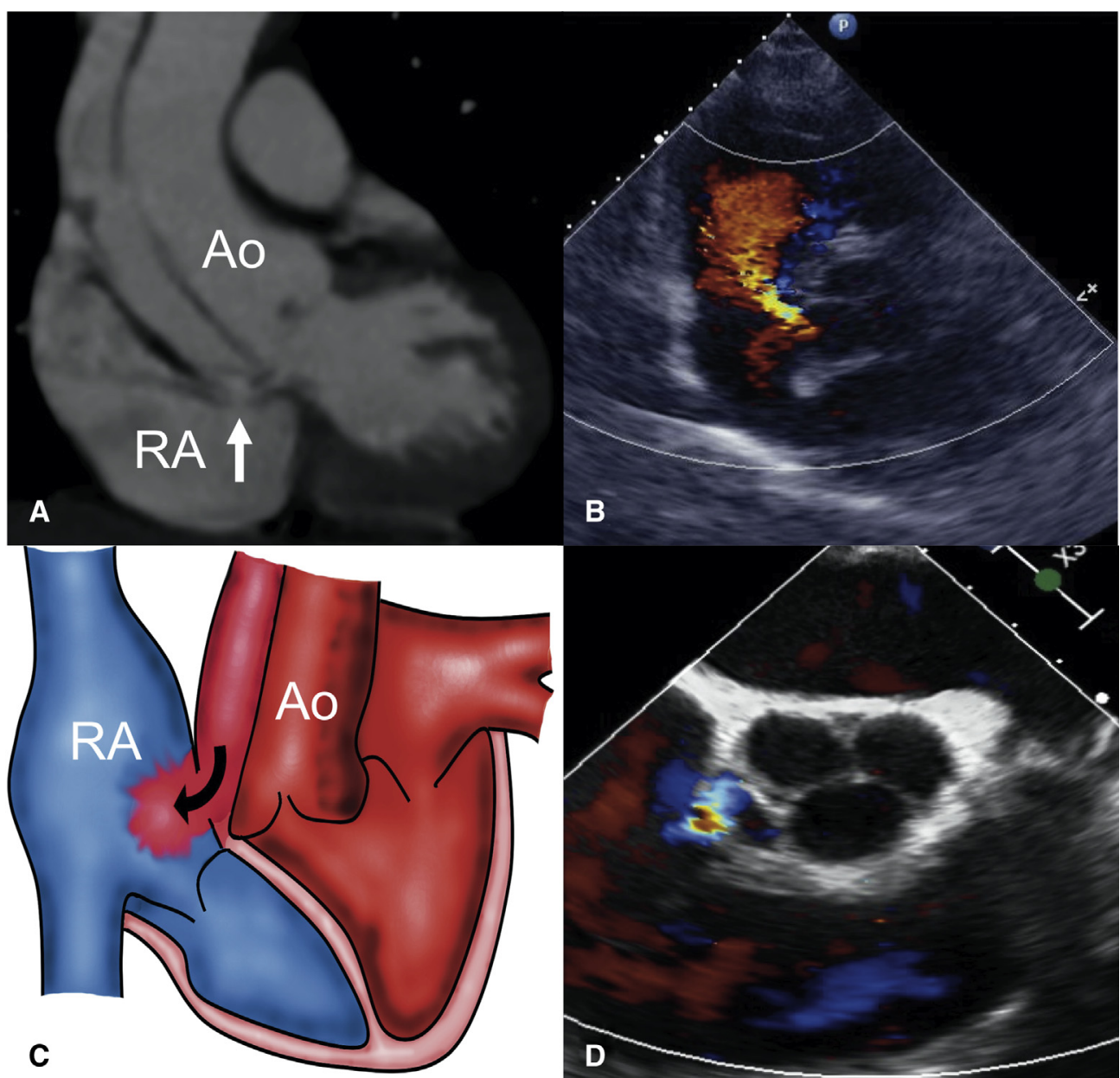

FIGURE 1. A, Preoperative contrast-enhanced computed tomography scan showing acute type A aortic dissection with an aorto-right atrial fistula. The arrow indicates the communication between the false lumen and the right atrium. B, Preoperative transthoracic echocardiography showing the left-to-right-shunt via an aorto-right atrial fistula. C, Schema of the fistula between the false lumen of the aorta and the right atrium. The intima of the aorta was intact. D, Transesophageal echocardiography showing the communication between the false lumen and the right atrium. Ao, Aorta; RA, right atrium.

the arch vessels were performed. CPB and aortic crossclamp times were 200 and 117 minutes, respectively.

The patient's postoperative course was uneventful, and postoperative TTE showed no residual shunt. Postoperative contrast-enhanced computed tomography also showed no communication between the aorta and the right atrium (Figure 2,D). He is doing well according to the 3-month follow-up findings. Informed consent was obtained from him.

\section{DISCUSSION}

Rupture into the pericardial space and cardiac tamponade are common but fatal complications of type A aortic dissections. However, rupture into the right atrium is a rare complication. ${ }^{2}$ Berman and colleagues ${ }^{3}$ emphasized the importance of 2-dimensional and Doppler TTE for the diagnosis of an aorto-right atrial fistula associated with aortic dissection. In our case, we performed a preoperative routine TTE in the emergency department and discovered the shunt flow from the aorta to the right atrium. The preoperative identification of the fistula allowed us to tailor the cannulation strategy of CPB and successfully repair the fistula via the right atrium and the aorta. We believe that preoperative screening using TTE is useful to find unexpected abnormalities such as a fistula.

Several repair techniques for aorto-right atrium fistulas have been reported. Matsuhisa and colleagues ${ }^{2}$ described a direct closure of the aorto-right atrial fistula. Hsu and colleagues ${ }^{4}$ performed an aortic root replacement for fistula repair. Direct sutures seem to be easy and simple but carry a high risk of bleeding by direct placement on the fragile adventitia. Aortic root replacement with excision of the ruptured adventitia is the most secure repair but is more invasive than other techniques. In our case, we closed the fistula using pericardial and Dacron 


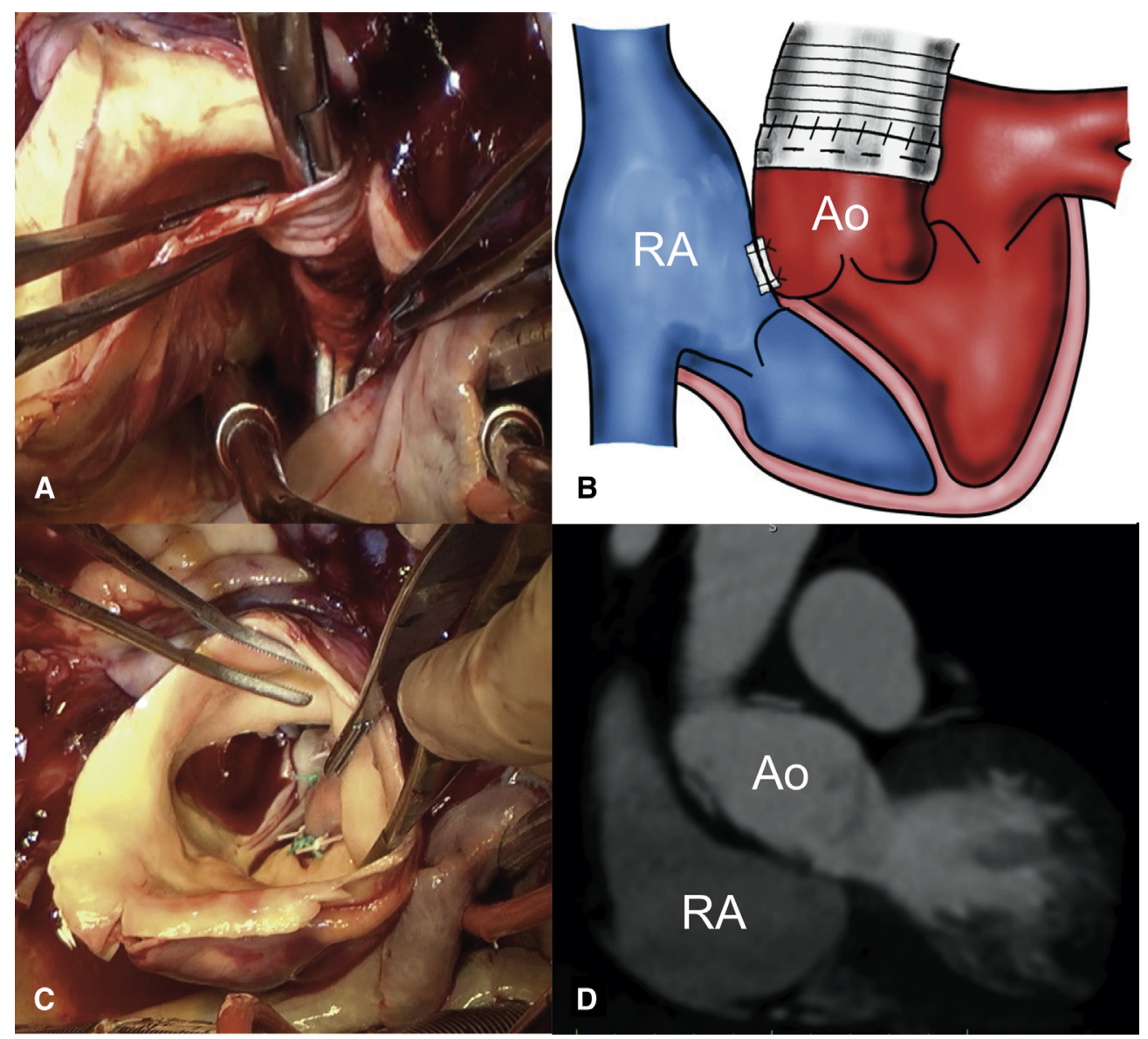

FIGURE 2. A, Intraoperative view showing the ruptured adventitia. The hole was communicated to the right atrium. B, Schema of the patch repair. The fistula was repaired using double patches. C, Intraoperative view showing the pericardial patch inside the aorta. D, Postoperative contrast-enhanced computed tomography scan demonstrating no communication between the aorta and the right atrium. RA, Right atrium; Ao, aorta.

patches. The use of 2 patches allowed us to avoid direct sutures on the adventitia and effectively close the fistula.

In conclusion, an aorto-right atrium fistula complicated with acute type A aortic dissection is rare. Patch repair

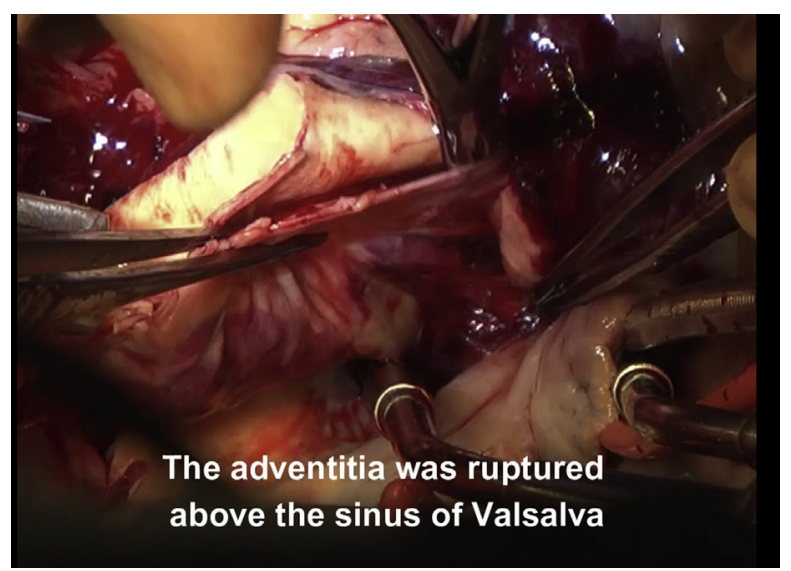

VIDEO 1. An intraoperative video that demonstrates repair of aorto-right atrium fistula. Video available at: https://www.jtcvs.org/article/S26662507(20)30041-9/fulltext. for the fistula is a simple and secure surgical treatment option.

\section{References}

1. Okamura H, Arakawa M, Takeuchi T, Adachi H. The fenestrated frozen elephan trunk technique for acute type A aortic dissection. J Thorac Cardiovasc Surg. 2018;156:e75-7.

2. Matsuhisa H, Obo H, Nakagiri K, Mukohara N, Shida T. Aorto-right atrial fistula caused by type A aortic dissection. Ann Thorac Surg. 2004;78:2173-5.

3. Berman AD, Come PC, Riley MF, Weintrub RM, Johnson RG, Aroesty JM. Two dimensional and doppler echocardiographic diagnosis of an aortic to right atrial fistula complicating aortic dissection. J Am Coll Cardiol. 1987;9:228-30.

4. Hsu RB, Chien CY, Wang SS, Chu SH. Aorto-right atrial fistula: a rare complication of aortic dissection. Tex Heart Inst J. 2000;27:64-6. 